\title{
Ice-sheet mass balance during the Last Glacial Maximum
}

\author{
Gilles Ramstein, ${ }^{1}$ Adeline Fabre, ${ }^{2}$ Sophie Pinot, ${ }^{1}$ Catherine Ritz, ${ }^{2}$ Sylvie Joussaume ${ }^{1}$ \\ ${ }^{1}$ Laboratoire de Modélisation du Climat et de l'Environnement, CE Saclay Bâtiment 709, Orme des Metisiers, 91191 Gif-sur-Yvette Cedex, France \\ ${ }^{2}$ Laboratoire de Glaciologie et de Géophysique de l'Environnement, Domaine Universitaire, 54 rue Molière, B.P. 96, \\ 38402 Saint-Martin-d'Hères Cedex, France
}

\begin{abstract}
In the framework of the Paleoclimate Modelling Intercomparison Project (PMIP), simulations of the Last Glacial Maximum (LGM) have been performed. More than 10 different atmospheric general circulation models (AGCMs) have been used with the same boundary conditions: sea-surface temperatures prescribed by CLIMAP (1981), ice-sheet reconstruction provided by Peltier (1994), change in insolation, and reduced $\mathrm{CO}_{2}$ content. One of the major questions is to investigate whether the simulations of the LGM are in equilibrium with the prescribed ice-sheet reconstruction. To answer this question, we have used two different approaches. First, we analyze the results of a set of LGM simulations performed with different versions of the Laboratoire de Météorologie Dynamique (LMD) AGCM and study the hydrologic and snow budgets over the Laurentide and Fennoscandian ice sheets. Second, we use the AGCM outputs to force an ice-sheet model in order to investigate its ability to maintain the ice sheets as reconstructed by CLIMAP (1981) or Peltier (1994).
\end{abstract}

\section{INTRODUGTION}

Since the first simulations of the Last Glacial Maximum (LGM), using atmospheric general circulation models (AGCMs) (Williams and others, 1974; see also Street-Perrot (1991) for a review), progress has been made both on the parameterization of physical processes and on the setting of boundary conditions. This last point is crucial because we perform "snapshot" experiments and compute the atmospheric response in equilibrium with different boundary conditions. Some of these conditions are very accurately defined, such as the insolation in the upper atmosphere (Berger, 1988), or atmospheric composition (mainly $\mathrm{CO}_{2}$ partial pressure) (Raynaud and others, 1993). Others, such as sea surface temperature (SST) or ice sheets, are more difficult to reconstruct. In the 1980 s and at the beginning of the 1990s, most simulations of the LGM used the CLIMAP (1981) SSTs (Broccoli and Manabe, 1987; Rind, 1987; Joussaume, 1993), whereas in the more recent ones AGCMs are coupled with a mixed-layer ocean and so the CLIMAP dataset is not used to prescribe SSTs (Webb and others, 1997).

Of course, the problem is different for ice-sheet reconstruction. Many AGCM experiments have studied the sensitivity of the LGM climate to the ice-sheet reconstruction (Shinn and Barron, 1989; Ramstein and Joussaume, 1995). Since 1994, the Peltier reconstruction has been available (Peltier, 1994). In the framework of the Paleoclimate Modeling Intercomparison Project (PMIP) (Joussaume and Taylor, 1995), this reconstruction has been chosen as a common boundary condition for all the models performing the LGM simulation.

The aim of this paper is to investigate the ice-sheet mass balance through different versions of the Laboratoire de Météorologie Dynamique (LMD) AGCM. To achieve this, we used two different approaches: the "direct" approach uses model outputs over the Laurentide and Fennoscandian ice sheets to analyze ice-sheet mass balance; the "coupled" approach uses model outputs (mainly temperature and precipitation) to force an ice-sheet model (Ritz and others, 1996), the physics and resolution of which are more refined, to investigate through a time-step simulation, whether ice sheets are maintained or melt (Fabre and others, 1997).

\section{METHODOLOGY}

\section{Direct approach}

Using the Peltier (1994) reconstruction, we performed the LGM simulations with three different versions of the LMD AGCM: LMD4, LMD4.3 and LMD5.3. Moreover for the LMD4 version, we constrained the LGM simulation with two different ice-sheet reconstructions: CLIMAP (1981) and Peltier (1994). The impact of the ice-sheet reconstruction on its mass balance is weaker than the changes in model parameterization (see below). Thus we decided to use only the more recent Peltier (1994) reconstruction for the experiments with LMD4.3 and LMD5.3. Moreover, all these runs were performed using prescribed SSTs deduced from CLIMAP (1981). In Table 1, we list a synthesis of the four different LGM runs.

Table 1. Synthesis of the LMD AGCM simulations of the Last Glacial Maximum

\begin{tabular}{ccc}
\hline Model version & Resolution & Ice-sheet reconstruction \\
\hline L.MD4 & $48 \times 36$ & CLIMAP (1981) \\
LMD4 & $48 \times 36$ & Peltier (1994) \\
LMD4.3 & $48 \times 36$ & Peltier (1994) \\
LMD5.3 & $64 \times 50$ & Peltier (1994) \\
\hline
\end{tabular}


Common features and differences between the three LMD versions

All the numerical experiments described below have been performed using the LMD AGCM. This is a gridpoint model using an Arakawa C-grid (Sadourny and Laval, 1984). The radiation scheme is the same as that used in the European Center for Medium-Range Weather Forecasts (ECMWF) model: the solar part is a refined version of the scheme developed by Fouquart and Bonnel (1980) and the terrestrial component is from Morcrette (1991). The boundary layer is parameterized using a diffusive equation in which the mixing coefficients depend on a prescribed length scale and a diagnostic determination of the turbulent kinetic energy. Condensation is parameterized separately for convective and non-convective clouds. Convection is parameterized using, in sequence, a moist adiabatic adjustment and a modified version of the Kuo (1965) algorithm. A prognostic equation for cloud water is included in the model: sources and sinks of cloud-condensed water are parameterized and the large-scale transport is taken into account.

\section{LMD4 and LMD4.3 improvements}

The main sink of cloud water is the precipitation process, which uses different parameterizations in the LMD4 and LMD4.3 versions (Le Treut and others, 1994).

(i) The first approach, used in the basic LMD4 version of the GCM, simply consists of prescribing a threshold for the precipitation of cloud water: the water in excess of the threshold is precipitated to the ground. It is necessary to distinguish between warm and cold clouds, and a lower threshold is used for clouds the top layer of which is below $-15^{\circ} \mathrm{C}$. This is a very simple way to account for the Bergeron process, by which ice clouds precipitate more efficiently. A validation of this first scheme in terms of cloud cover, using the International Satellite Cloud Climatology Project (ISCCP) data over the Meteosat area, gave good results (Le Treut and $\mathrm{Li}, 1988$ ).

(ii) Deficiencies of the simple parameterization described above became obvious when comparisons with Scanning Multichannel Microwave Radiometer (SMMR) estimates showed that the integrated cloud water content was too low. In addition, comparisons with Earth Radiation Budget Experiment (ERBE) data showed that the longwave cloud forcing was too large at high latitudes. The discontinuities introduced by the threshold approach also presented a serious problem for further comparisons with observations (Yu and others, 1996), as well as climate sensitivity studies (Li and Le Treut, 1992). The LMD4.3 version of the model was therefore developed. Cloud precipitation in the liquid phase is described using a formula first proposed by Sundqvist (1981). It allows a transition from a thin, nonprecipitating to a thick, strongly precipitating cloud regime that is smoother than with the threshold method. Precipitation from ice clouds is treated through a simple ice-sedimentation mechanism, in which the precipitation rate depends on the terminal velocity of the falling crystals. Finally, a linear transition between ice and water clouds is also defined between $0^{\circ} \mathrm{C}$ and $-15^{\circ} \mathrm{C}$. The fraction of a given cloud in the liquid phase decreases linearly from 1 to 0 between these two temperatures.

The water condensed in convective clouds is retained as cloud water, and precipitates according to the same parameterizations as those used in the stratiform case. This feature, which is not shared by many models, partly explains the strong association of convective or stratiform clouds with the intertropical convergence zone. This is a notable feature of the LMD GCM.

\section{LMD4.3 and LMD 5.3 improvements}

The main new features of the LMD5.3 version are the treatments of the surface and the surface-atmosphere interaction. This version includes a sub-grid representation of fractional sea-ice cover. A distribution between eight biomes represents, for each cell, the type of vegetation. The surface scheme representing the hydrologic exchanges between atmosphere and biosphere is SECHIBA (Schématisation des Échanges Hydriques à l'Interface Biosphère Atmosphère; Ducoudré and Laval, 1993). Albedo is computed from the values of snow depth, cover and age, and vegetation cover (Chalita and Le Treut, 1994).

\section{Resolution}

We use two different resolutions. For LMD4 and LMD4.3, we use the low resolution: 48 points regularly spaced in longitude, 36 points regularly spaced in sine of the latitude and 11 vertical levels. For the LMD5.3 version, we use the standard resolution, which has a better horizontal resolution: 64 points in longitude and 50 points in latitude. Each horizontal gridcell has a constant area. The vertical coordinate is the normalized pressure.

\section{Ice-sheet reconstruction}

A major difference between present and LGM climate is the large ice sheets covering northwestern Europe (Fennoscandia) and the northern part of North America (Laurentide). The shape and size of these ice sheets have a major impact on the atmospheric dynamics over the Northern Hemisphere during the LGM, especially concerning the split of the jet that may have occurred as a result of Laurentide ice sheet influence on planetary waves (Kutzbach and Guetter, 1986; Rind, 1987). Denton and Hughes (1981) provided two reconstructions referenced as MIN and MAX, corresponding to eustatic sea-level rise values of $127 \mathrm{~m}$ and $163 \mathrm{~m}$. Peltier (1994) showed that even the MIN reconstruction was excessive and proposed a new reconstruction based on a gravitationally self-consistent theory of relative sealevel changes. It corresponds to an eustatic sea-level rise of $105 \mathrm{~m}$. In Figure 1, we show the change in elevation between the LGM and the present climate for the reconstructions devised by Peltier (1994) (for both resolutions) and CLIMAP (only the low resolution is used). The extent of the ice sheets is not very different, but the elevation is $1500 \mathrm{~m}$ higher over the Laurentide, and about $1000 \mathrm{~m}$ higher over Fennoscandia in the CLIMAP reconstruction. Moreover, the smaller sealevel rise in Peltier's reconstruction leads to a reduction of emerged lands. We take this into account and use different sea-land masks for the two simulations.

\section{Coupled approach: AGCM outputs driving an ice- sheet model}

The ice-sheet model is a three-dimensional (3-D) thermomechanically coupled model. It takes into account the coupling between temperature and velocity fields, and belongs to the same category of ice-sheet models as those developed by Huybrechts and T'siobbel (1995) and Greve and Hutter (1995). The evolution of ice-sheet geometry is a function of mass balance, velocity, temperature fields and bedrock position. The ice-sheet model (see Ritz and others, 1996) for a comprehensive description) was used successfully on the 

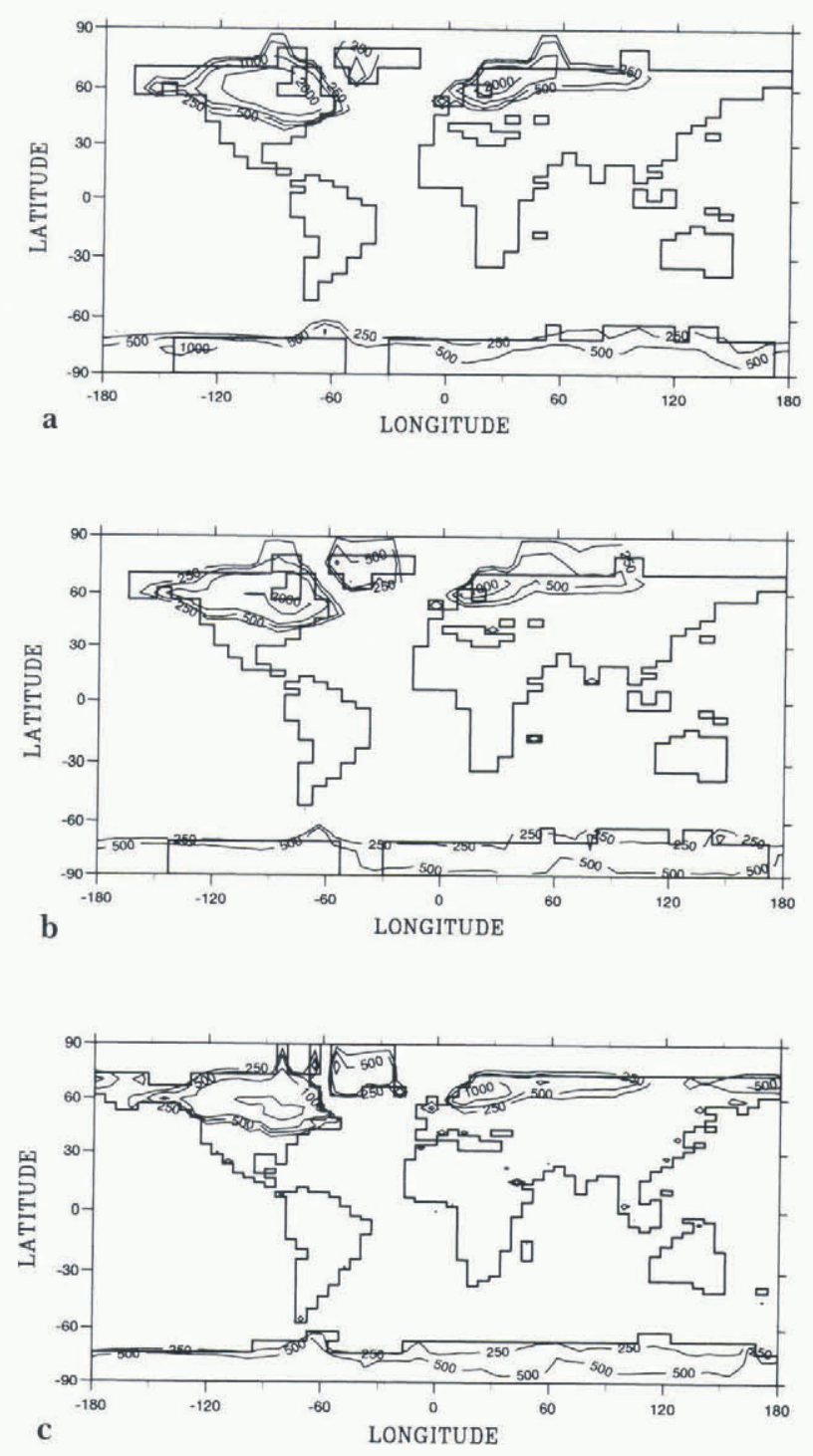

Fig. 1. Ice-sheet reconstructions and AGCM grid for (a) CLIMAP (1981) ice sheets interpolated on the $48 \times 36$ grid used for LMD4, (b) Peltier (1994) ice sheets interpolated on the $48 \times 36$ grid used for LMD4 and LMD4.3, (c) Peltier (1994) ice sheets interpolated on the $64 \times 50$ grid used for LMD 5.3

Greenland ice sheet (Fabre and others, 1995) and has since been extended to the whole of the Northern Hemisphere for present and LGM climates (Fabre and others, 1997). We now describe briefly the mass-balance calculation.

The mass balance is the sum of four separately computed terms: accumulation, ablation, calving and melting at the bottom of the ice sheet. Accumulation is a key factor computed from interpolated AGCM temperatures and precipitation. Ablation is computed using the "positive degree day method" (Reeh, 1991). there is no treatment of ice shelves in the model. Calving is computed by setting the ice thickness to zero on a "coastal line" determined by the sea level. A sealevel drop is taken into account for the LGM corresponding to $105 \mathrm{~m}$ for the Peltier (1994) reconstruction, and of $163 \mathrm{~m}$ for the CLIMAP (1981) maximum reconstruction. The isostatic variation of the bedrock, resulting from an evolving ice load, is governed by two components: an asthenospheric flow with a characteristic response time of 3000 years and a lithospheric rigidity that is taken into account by the spatial shape of the deflection.

\section{ANALYSIS OF THE RESULTS}

\section{Direct approach}

The climate of the LGM is globally colder than present. In all of these simulations, the annual mean difference of temperature between the LGM and a present control run is $-3.3^{\circ} \mathrm{C}$ (Ramstein and Joussaume, 1995; Ramstein and others, in press). Temperature change is a strong function of latitude, with a cooling of more than $10^{\circ} \mathrm{C}$ at high latitudes, and only $1{ }^{\circ} \mathrm{C}$ for the tropics. Moreover, the temperature decrease is large over the ice sheets, especially in the summer when orography and albedo impacts are superimposed, reaching values between -15 and $-25^{\circ} \mathrm{C}$, depending on the versions used. Another region of drastic cooling is the northern Atlantic Ocean. This is due to sea-ice extent and change in atmospheric circulation (mainly splitting of the jet that brings cold polar air masses towards the North Atlantic (Kutzbach and Guetter, 1986; Rind, 1987)). In this area, the annual mean temperature cooling is about $25^{\circ} \mathrm{C}$.

The hydrologic cycle is also strongly modified. A colder climate leads to a global decrease in the hydrologic cycle, whereas the water transport from Equator-to-Pole is increased due to the enhancement of the Hadley cells (Ramstein and others, in press). The decrease is weaker and more uniform in winter $(-8 \%$ of water vapor in the atmosphere), and more pronounced and localized over the Northern Hemisphere mid and high latitudes $(-16 \%)$ during summer (Ramstein and others, in press).

In this paper, we will focus our discussion on the Laurentide and Fennoscandian ice-sheet mass balance through different versions of the LMD AGCM. To quantify the impact of the ice-sheet reconstructions on mass balance, we first performed two simulations using LMD4 and two different ice-sheet reconstructions (CLIMAP (1981) and Peltier (1994)). In Figure 1, we show the orographic difference between the LGM and the present for the CLIMAP (1981) ice-sheet reconstruction interpolated on the low-resolution horizontal grid, and the Peltier (1994) reconstruction interpolated on the low- and standard-resolution horizontal grid. From these maps, we define two spatial areas covering the Laurentide and Fennoscandian ice sheets. In Table 2, we present for each ice sheet all the simulations of the annual summer and winter averages of the water balance (differences between precipitation and evaporation, plus runoff), each term of this balance equation, and surface temperature. We also present the mean annual net snow accumulation (snowfall minus snowmelt). For all LGM runs, we observe an annual positive hydrologic balance, but the accumulation has different amplitudes within the different versions.

Table 2 shows an important feature: the seasonal behavior is different for LMD5.3 compared to the LMD4 models. For the previous versions, there is a strong accumulation during winter, and a weaker "melting" during summer because temperatures reach positive values. For LMD5.3, accumulation occurs for both seasons with the same order of magnitude and, over Fennoscandia, more accumulation occurs during March, April and May and during September, October and November (not shown).

Over both ice sheets, LMD5.3 has accumulation rates 3-5 times higher than the other versions (LMD4 and LMD4.3, respectively). This increase results partly from cooler temperatures that allow more snowfall in summer, 
Table 2. Annual, summer and winter averages over Laurentide and Fennoscandian ice sheets of the surface temperature $\left(0^{\circ} \mathrm{C}\right)$, water mass balance in $\mathrm{mm}^{-l}$, (precipitation, evaporation, runoff) and annually averaged net snow accumulation in $\mathrm{cm}$ for all LGM simulations

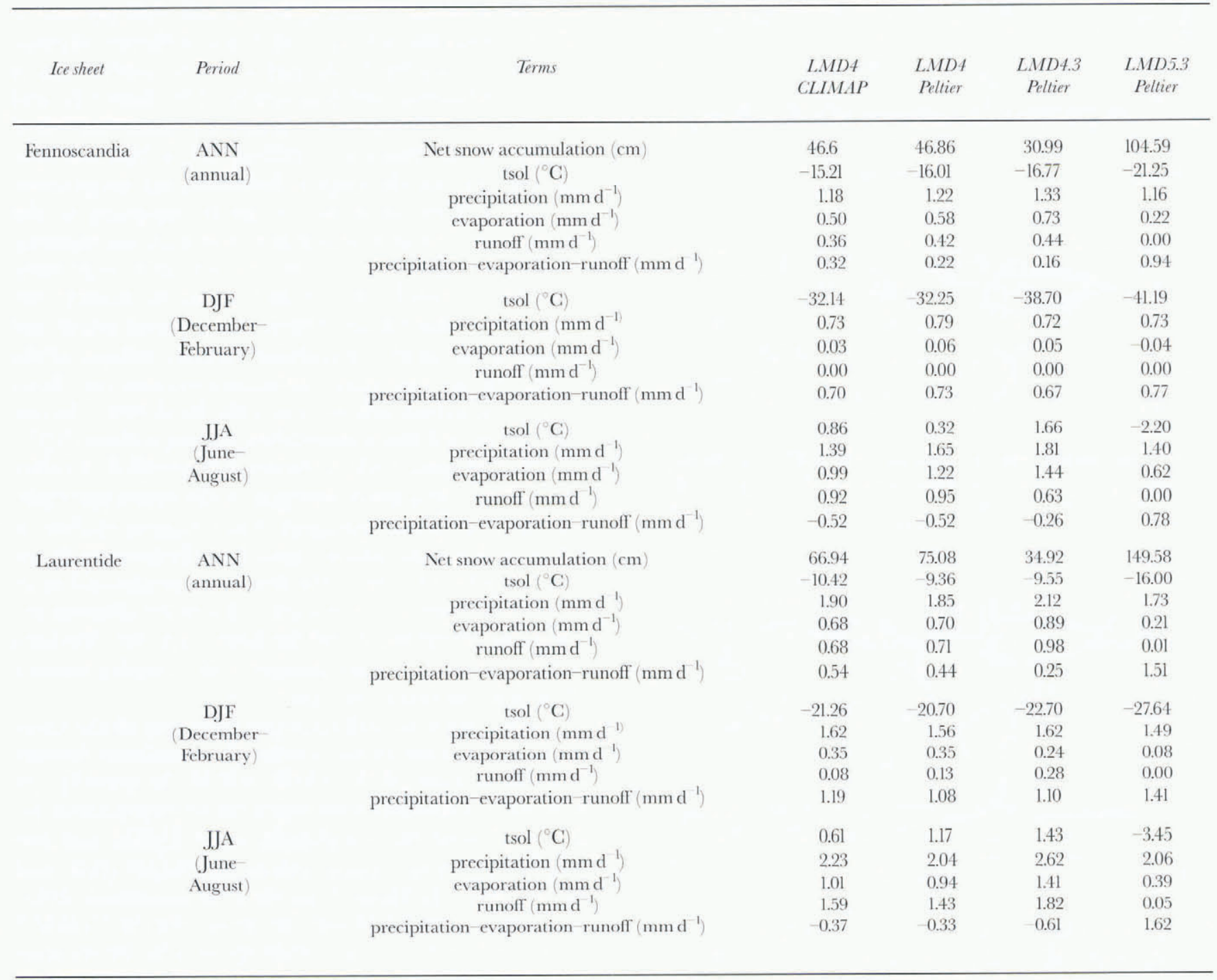

but it is mainly due to the drastic decrease in evaporation and runoff (Table 2). In contrast to the other versions, LMD5.3 always gives negative summer temperatures over the ice sheets, which lead to a severe decrease of evaporation and inhibit the runoff.

The ice-sheet mass balance produced by LMD 4.3 is the lowest (a factor of 2 lower than LMD4). The main reason for this decrease is that this version has the highest summer temperatures, and therefore the highest evaporation and runoff rates during summer. This compensates for the slight precipitation increase, and leads to a nearly balanced water budget. The colder surface temperatures of LMD5.3, especially in summer, are the consequence of the higher snow albedo specified over the ice sheet (Pinot, 1995). If we now compare the simulations performed with LMD4 using the two different ice-sheet reconstructions, the accumulation rates for both ice sheets are higher than for LMD4.3. This is mainly due to lower, positive, summer surface temperatures. There are very small differences in the water balance between the two LMD4 simulations using different ice sheets. These results indicate that the impact of the different parameterizations used in the models on ice-sheet mass balance is greater than the changes in the ice-sheet reconstructions.
To simplify the description of the results, the LMD5.3 simulation, which is the most recent version and has the highest resolution run, is presented in more detail. Figure 2 gives the annual mean total precipitation and snowfall for
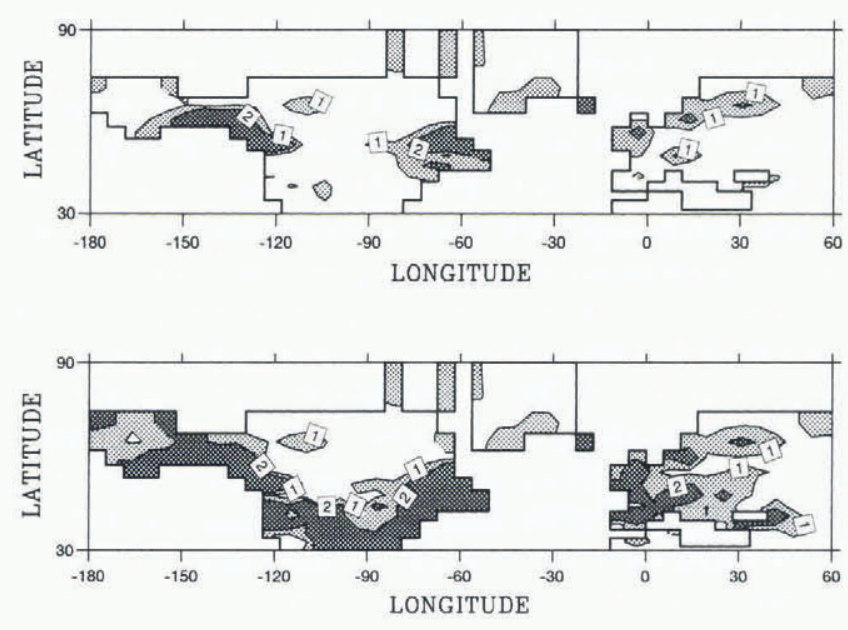

Fig. 2. Annual mean for LMD5.3 LGM simulation. Top: snowfall $\left(\mathrm{mm} \mathrm{d}^{-1}\right)$ and bottom: precipitation $\left(m m d^{-1}\right)$. 
this simulation. If most of the precipitation over the ice sheet is snowfall, then the hydrologic balance discussed above is indeed consistent with the net snow accumulation. Precipitation is very low over the central Laurentide, but higher on the eastern and western sides (where values as high as $10 \mathrm{~mm} \mathrm{~d}^{-1}$ are reached). Over the northeastern Pacific there are high precipitation rates due to the warm LGM SST given by the CLIMAP (1981) reconstruction. This region is an important source of the water vapour that produces the high precipitation rates over the extreme western part of the Laurentide ice sheet. On the eastern side, there are also high precipitation rates corresponding to winter storms occurring at the location of the sea-ice extent, and the Icelandic winter low. Over the Fennoscandian ice sheet, precipitation and snowfall are also similar, having low values at about $1 \mathrm{~mm} \mathrm{~d}^{-1}$.

To understand better the snow mass balance over the ice sheets in LMD5.3, we have plotted the annual mean snowfall, snowmelt, and snow accumulation during the 16 simulated years of the run on the same diagram (Fig. 3). Once more, we observe that there is an important snow accumulation over the extreme western and eastern parts of the Laurentide ice sheet, but there is little or no accumulation over the central region. Over Fennoscandia, there is a more homogeneous accumulation. The data presented in Figure 3 suggest, therefore, that snow accumulation reflects the spatial pattern of snowfall. Melting also occurs over the same areas, but is weaker due to very cold temperatures and is five times lower than the snowfall rate. To compare this result to the net snow accumulation of the other model versions, Figure 4 shows the net snow accumulation for all the LGM runs. Snow accumulation is computed over the length of the run, which is 16 years for LMD5.3 and LMD4.3, but only 6 years for L.MD4.

To compare more easily the different plots shown in Figure 4 , we divided by three the scale used for these two last runs. (For annual net accumulation, see also the values in Table 2.) Again, we observe that the largest net accumulation occurs in LMD5.3. The geographical pattern of the net snow accumulation is similar for all the model versions, with an area of accumulation localized on the western and eastern margins of the Laurentide ice sheet, and a more homogeneous distribution over the Fennoscandian ice sheet. This spatial similarity, despite differences in the amplitude, shows that prescribed SSTs that are a common
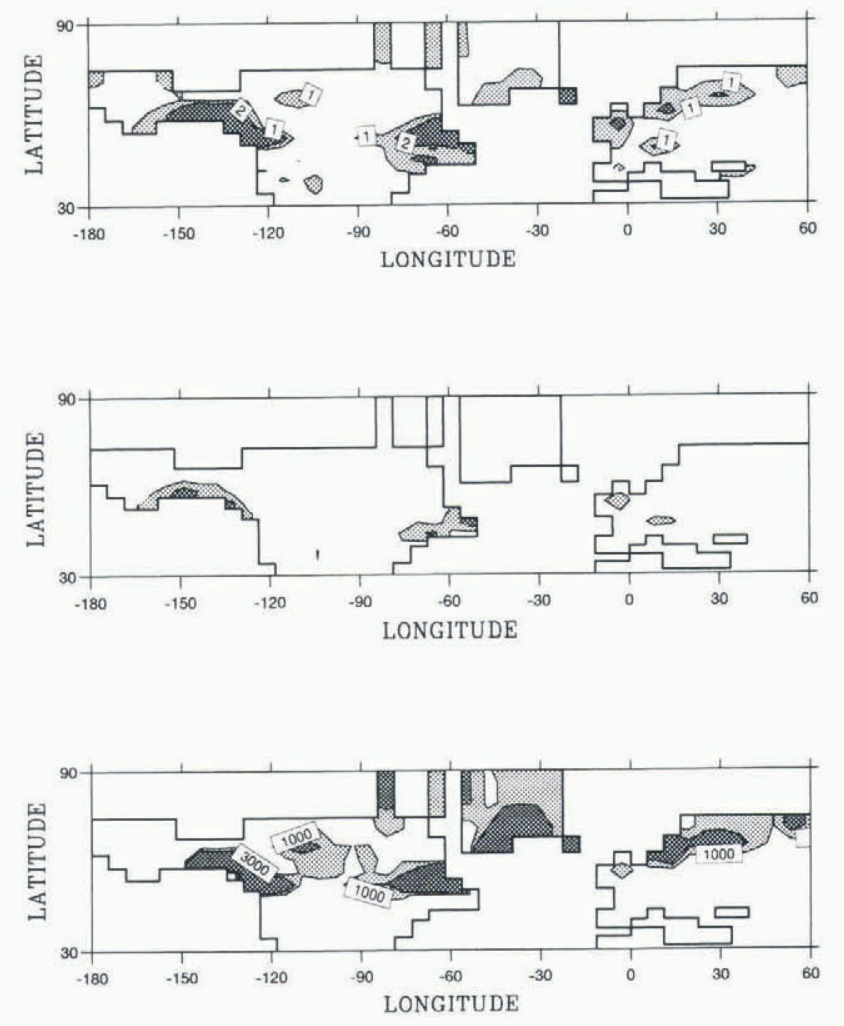

Fig. 3. Annual mean for LMD5.3 LGM simulation. Top: snowfall ( $\left.m m d^{-}\right)$, middle: snow melt ( $m m^{-}$) and net snow accumulation for the 16 years of the run $\left(\mathrm{mm} \mathrm{d}^{-1}\right)$.

feature of all these runs (see the methodology section) play a major role in the snowfall pattern. The warm Pacific provides high snowfall on the western margin of the Laurentide, while winter storms, localized over the northwestern Atlantic, contribute to snowfall on the eastern margin. The prescribed SST appears to be more important than the differences between model versions or ice-sheet reconstructions.

\section{Ice-sheet model driven by AGCM outputs}

In the ice-sheet model, Peltier (1994) or CLIMAP (1981) reconstructions may be used as an initial condition for the LGM runs. To account for the isostatic rebound, a crude approximation is used in which the bedrock lowering is a third of the ice thickness. The isostatic rebound is then com-
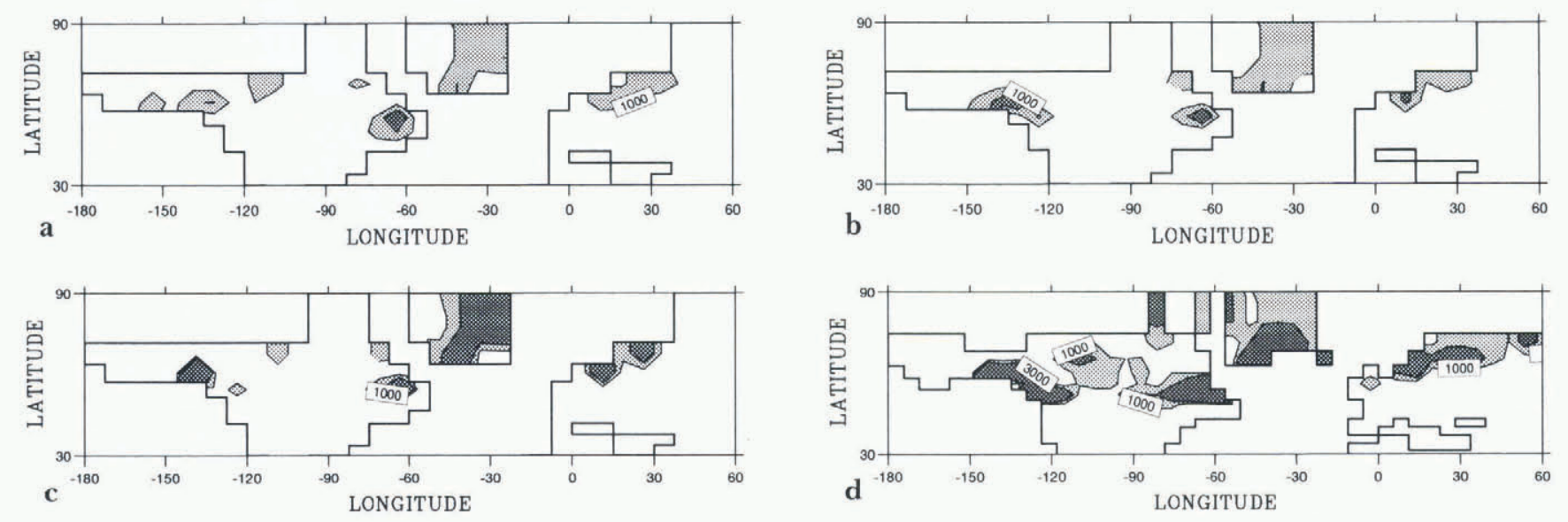

Fig. 4. Snow accumulation for LGM simulations. (a) LMD4 CLIMAP (1981) 5 year run, (b) LMD4 Peltier (1994) 5 year run, (c) LMD4.31.5 year run, (d) LMD5.315year run. 
puted by the model. In the ice-sheet model, snow accumulation and ablation are derived from AGCM outputs. Snow accumulation is computed from annual mean surface temperature and precipitation, and ablation is computed from summer (June, July and August) and annual surface temperatures. Note that these AGCM fields are not directly used in the ice-sheet model (see Fabre and others (1997) for a detailed discussion of the coupling method).

In the following section, we describe the treatment of the AGCM output before it is used in the ice-sheet model. A major problem is the difference in resolution of both models. The initial database provided by Peltier (1994) has a $1 \times 1^{\circ}$ resolution, while CLIMAP (1981) has a $2 \times 2^{\circ}$ resolution, which is interpolated on the Cartesian grid of the ice-sheet model $(50 \times 50 \mathrm{~km})$. The interpolation on the AGCM grid smoothes the elevation because of the coarser gridboxes. For temperature fields, we used a "reconstructed" temperature defined as the difference of temperature between the LGM and the control (from AGCM outputs), which is added to present climatology:

$$
T_{\text {rec }}=T_{\text {lgm }}-T_{\text {ctrl }}+T_{\text {clim }} .
$$

The reason for such a methodology is that the CLIMAP dataset only gives August and February SST, and it is better to keep a realistic seasonal cycle by using the "reconstructed" surface temperatures. These values are then corrected for the elevation difference $\left(A l t_{\text {new }}\right.$ and $\left.A l t_{\text {old }}\right)$ to account for the better resolution of the ice-sheet model. The temperature gradient chosen is $8^{\circ} \mathrm{C} \mathrm{km}^{-1}$ as observed in polar regions. Thus:

$$
T_{\text {new }}=T_{\text {old }}-0.008 \times\left(A l t_{\text {new }}-A l t_{\text {old }}\right) .
$$

Using this method leads to negative values for some gridpoints in precipitation fields, so we used a ratio rather than a difference:

$$
\text { Prec }_{\mathrm{rec}}=\left(\text { Prec }_{\mathrm{lgm}} / \text { Prec }_{\mathrm{ctrl}}\right) \times \text { Prec }_{\mathrm{clim}} .
$$

As previously noted, all LGM simulations have been performed using prescribed SST, which results, for the icesheet model, in a discontinuity in coastal regions' surface temperatures because these are computed over land by the model. This discontinuity has consequences for the hydrologic cycle, and to minimize them we use the AGCM surface air temperature at $2 \mathrm{~m}$ height that is computed for all gridpoints.

Accounting for all these problems before coupling, we performed three 20000 runs using AGCM LMD5.3 and LMD4.3 outputs and the Peltier (1994) reconstruction as boundary conditions, and the LMD4 outputs with the CLIMAP ice-sheet reconstruction. The results are shown in Figure 5. Using LMD5.3 outputs, the ice-sheet model maintains the ice sheet, whereas with other runs, the Laurentide and Fennoscandian ice sheets collapse. For the run coupled with LMD5.3 outputs, the best results are the maintenance of the Laurentide and Fennoscandian ice sheets in a steady state near the Peltier reconstruction and the absence of an ice cap over Siberia and Alaska, which is consistent with data for the LGM. A weaker point is the large accumulation decrease over Greenland, which leads to a lowering of the ice sheet. However, this may be due to the AGCM coarser grid at high latitudes.

For LMD4.3, the Fennoscandian and Greenland ice sheets survive, despite an important lowering, but the Laurentide ice sheet is reduced to a longitudinal belt on the western part of North America. This may be due to the pre-
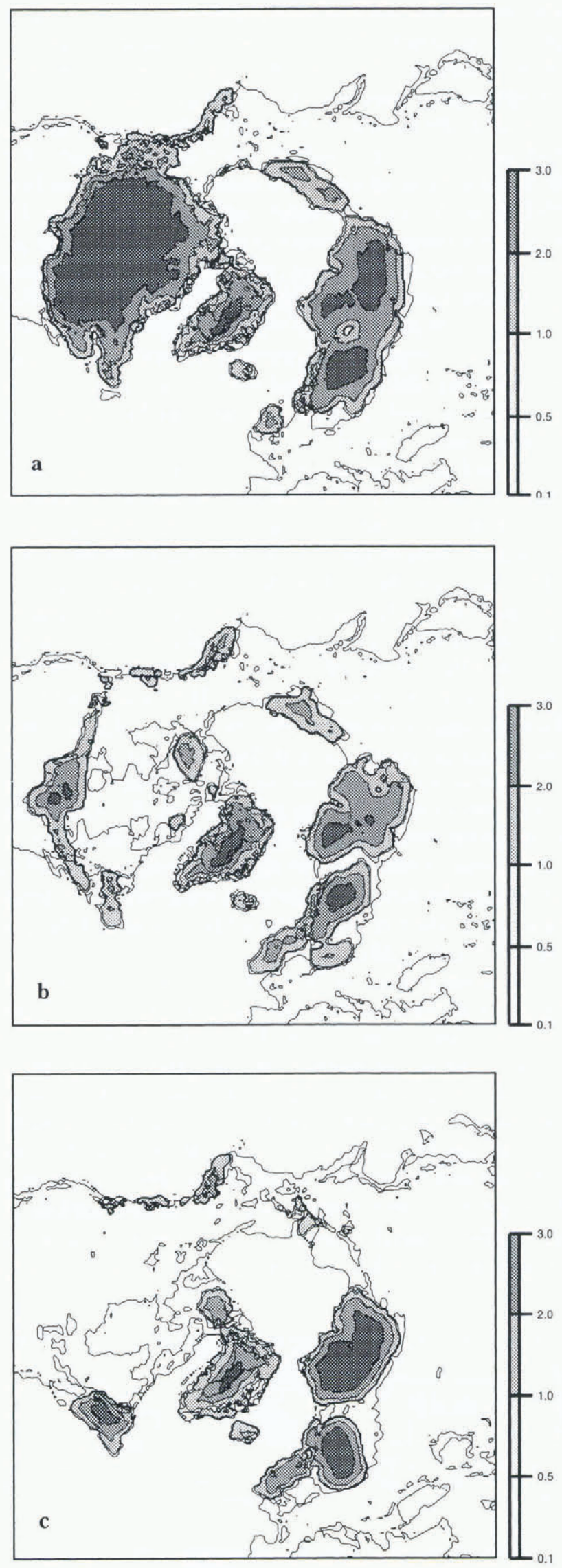

Fig. 5. Results of the ice-sheet model. The steady state is obtained after 20000 years integration of the model. (a) Inputs are deduced from LMD5.3 outputs and Peltier (1994) reconstruction is the initial condition, $(b)$ inputs are deduced from LMD4.3 outputs and Peltier (1994) reconstruction is the initial condition, (c) inputs are deduced from LMD4 outputs and CLIMAP (1981) reconstruction is the initial condition. The thin line represents the land over sea level. 
scribed CLIMAP (1981) SSTs, which give a warm pool over the mid latitudes of the north Pacific that are able to produce moisture that precipitates over the continent. Finally, LMD4 outputs show that, despite the fact that we start with the CLIMAP ice sheets that are $1000 \mathrm{~m}$ higher, a weaker extent of the Laurentide ice sheet, but a slightly higher Fennoscandian ice sheet, are obtained.

The ice-sheet model is therefore very sensitive to AGCM outputs. The best result is obtained with LMD5.3 in this approach, whereas in the previous approach, the weaker ice-sheet mass balance was obtained for LMD 4.3

\section{CONCLUSIONS}

We investigated, through two different methods, the mass balance of the ice sheets for the LGM. We expect little or no net snow accumulation. Are these tools able to tell us whether the prescribed ice sheets (Peltier or CLIMAP) are in equilibrium or near the equilibrium with the computed LGM climate? The answer to this question is not clear cut because our results suggest that the conclusions vary depending on the methodology used. Moreover, these results are very different from those of Hall and others (1996) who found that for the model developed by the UK Universities' Global Atmospheric Modeling Program, the maintenance of ice sheets was due to a net accumulation in the central part and a melting at the edges. In the present research, we found that there is still accumulation over the ice sheets at the LGM. However, these results are quite different for the LMD5 and LMD4 versions. LMD5 surface temperatures are colder and always below freezing, which leads to a decrease of evaporation and to a high accumulation. In the other model versions, the summer temperatures are above freezing point and ice-sheet mass balance is reduced to lower values.

In the method using LGM AGCM inputs and an icesheet model, the best result is obtained with LMD5.3 inputs, which is the only one that maintains the ice sheet. The fact that this version is the best candidate to maintain the ice sheet is not surprising because it has the highest accumulation and also the highest resolution. What is puzzling is why the LMD4.3 version, which from the direct approach seems the closest to a zero mass balance, gives such poor results when using an ice-sheet model. There are two main reasons. First, in the direct approach the high LMD4.3 summer surface temperatures enhance summer melting, which partly compensate for winter snowfall, but in the coupled approach we use $2 \mathrm{~m}$ height air surface temperatures that strongly dampen the summer temperature differences between the LMD5.3 and earlier versions. Secondly, the coarser grid of the LMD4.3 version is more difficult to couple with the smaller ice-sheet Cartesian grid, especially when using precipitation.

A way to avoid the first problem is to use a LGM simulation with computed SSTs that will allow us to use directly the surface temperature in the ice-sheet model. This simulation has already been performed, and will be coupled with the ice-sheet model. A major advance in this topic should be achieved through the Ice Sheet Mass Balance Sub-Project led by D. Pollard in the framework of the PMIP program (Joussaume and Taylor, 1995). More than 15 model results for LGM simulation using the same boundary conditions, will then be analyzed in terms of ice-sheet mass balance.

\section{ACKNOWLEDGEMENTS}

We gratefully acknowledge the Laboratoire de Météorologie Dynamique (CNRS, Paris, France) for providing us with their GCM, J. Jouzel for fruitful discussion, D. Lewden for participating in the simulations and J.Y. Peterschmitt (LMCE) for the graphic outputs.

\section{REFERENGES}

Berger, A. 1988. Milankovitch theory and climate. Rev. Geophys., 26 4), 624657.

Broccoli, A. J. and S. Manabe. 1987. The influence of continental ice, atmospheric $\mathrm{CO}_{2}$, and land albedo on the climate of the last glacial maximum. Climate Dyn., 1 2, 87-99.

Broccoli, A. J. and E. P. Marciniak. 1996. Comparing simulated glacial climate and paleodata: a re-examination. Paleoceanography, 11 (1), 3-14.

Chalita, S. and H. Le Treut. 1994. The albedo of temperate and boreal forest and the Northern Hemisphere climate: a sensitivity experiment using the LMD AGCM. Climate Dyn., 10 4 5, 231-240.

Climap Project Members. 1981. Seasonal reconstructions of the Earth's surface at the last glacial maximum. Boulder, CO, Geological Society of America. Map Chart MC:-36.

Denton, G. H. and T.J. Hughes, eds. 1981. The last great ice sheets. New York, etc., John Wiley and Sons.

Ducoudré, N. and K. Laval. 1993. SECHIBA, a new set of parameterization of the hydrologic exchanges at the land atmosphere interface within the L.MD AGCM. f. Climate, 6 2, 249- 273.

Fabre, A., A. Letréguilly, C. Ritz and A. Mangeney. 1995. Greenland under changing climates: sensitivity experiments with a new three-dimensional ice-sheet model. Ann. Glaciol., 21, 1-7.

Fabre, A., C. Ritz and G. Ramstein. 1997. Modelling of Last Glacial Maximum ice sheets using different accumulation parameterizations. Ann. Glaciol., 24, 223-228.

Fouquart, Y. and B. Bonnel. 1980. Computations of solar heating of the Earth atmosphere: a new parameterization. Beitr. Phys. Almos., 53, $35-62$.

Greve, R. and K. Hutter. 1995. Polythermal three-dimensional modelling of the Greenland ice sheet with varied geothermal heat flux. Ann. Glaciol., 21. 8-12.

Hall, N. M.J., P.J. Valdes and B. Dong. 1996. The maintenance of the last great ice sheets; a UGAMP GCM study. J. Climate, 21, $1004-1019$

Huybrechts, P. and S. T'siobbel. 1995. Thermomechanical modelling of Northern Hemisphere ice sheets with a two-level mass-balance parameterization. Ann. Glaciol., 21,111-116.

Joussaume, S. 1993. Paleoclimatic tracers: an investigation using an atmospheric general circulation model under ice age conditions. 1: Desert dust. J. Geophys. Res., 98 D2, $2767-2805$.

Joussaume, S, and K. Taylor. 1995. Status of the paleoclimate modeling intercomparison project (PMIP). In WCRP-2, First International AMIP Scientific Conference, 15-19 May 1995, Monterey, CA. Proceedings. Geneva, World Meteorological Organisation. World Climate Research Programme, 415 - 430. (WMO TD 732, WCRP-92.)

Kuo, H.L. 1965. On formation and intensification of tropical cyclones through latent heat release by cumulus convection. 7. Atmos. Sci., 22, $1482-1497$.

Kutzbach, J. E. and P.J. Guetter. 1986. The influence of changing orbital parameters and surface boundary conditions on climate simulations for the past 18,000 years. f. Atmos. Sci., 43 16), 1726-1759.

Le Treut, H. and Z. X. Li. 1988. Using Meteosat ISCCP data to validate a prognostic cloud generation scheme. Almos. Res., 21, 273- 292.

Le Treut, H., Z.. X. Li and M. Forichon. 1994. Sensitivity of the LMD general circulation model to greenhouse forcing associated with two different cloud water parameterizations. J. Climale, 7 12), 1827-1841.

Li, Z. X. and H. Le Treut. 1992. Cloud-radiation feedbacks in a general circulation model and their dependence on cloud modelling assumptions. Climate Dyn., 7, 133-139.

Morcrette, J. -J. 1991. Radiation and cloud radiative properties in the ECMWF operational weather forecast model. f. Geophys. Res., 96 D5), $9121-9132$.

Peltier, W. R. 1994. Ice age paleotopography. Science, 265(5169), 195- 201.

Pinot, S. 1995. Simulation du climate du dernier maximum glaciaire: sensibilité aux diffërentes paramétrisations utilisées. Rapport de stage.

Ramstein, G. and S. Joussaume. 1995. Sensitivity experiments to sea surface temperatures, sea-ice extent and ice-sheet reconstruction for the Last Glacial Maximum. Ann. Glaciol, 21,343-347.

Ramstein, G., H. Le Treut, V. Sérafini, M. Forichon and S. Joussaume. In press. Cloud processes associated with past and future climate changes. 
Climate Dyn..

Raynaud, D., J. Jouzel, J. -M. Barnola, J. Chappellaz, R. J. Delmas and C. Lorius. 1993. The ice record of greenhouse gases. Science, 259 (5097), 926934.

Reeh, N. 1991. Parameterization of melt rate and surface temperature on the Greenland ice sheet. Polarforschung, 59 (3), 1989, 113-128.

Rind, D. 1987. Components of the ice age circulation. J. Geophys. Res., 92 (D4), $4241-4281$.

Ritz, C., A. Fabre and A. Letréguilly. 1996. Can an ice-sheet model simulate the present Greenland ice-sheet? Climale Dyn., 13(2), 11- 24.

Sadourny, R. and K. Laval. 1984. January and July performance of the LMD general circulation model. In Berger, A. and C. Nicolis, eds. New perspectives in climate modeling. Amsterdam, Elsevier, 173-198.

Shinn, R. A. and E. J. Barron. 1989. Climate sensitivity to continental ice sheet size and configuration. 7. Climate, 2 12), 1517-1537.

Street-Perrott, F. A. 1991. General circulation (GCM) modelling of palaeoclimates: a critique. Holocene, 1 (1), 74-80.

Sundqvist, H. 1981. Prediction of stratiform clouds: results of 5-day forecast with a global model. Tellus, 33, $242-253$.

Webb, R. S., D. H. Rind, S.J. Lehman, R.J. Healy and D. Sigman. 1997. Influence of oceanic heat transport on the climate of Last Glacial Maximum. Nature, 385, 695-699.

Williams, J., R. G. Barry and W. M. Washington. 1974. Simulation of the atmospheric circulation using the NCAR global circulation model with ice age boundary conditions. F. Appl. Meteorol., 13 (3), 305-317.

Yu, W., M. Doutriaux, G. Seze, H. Le Treut and M. Desbois. 1996. A methodology study of the validation of clouds in GCMs using ISCCP satellite observations. Climate Dyn., 12, 389-401. 